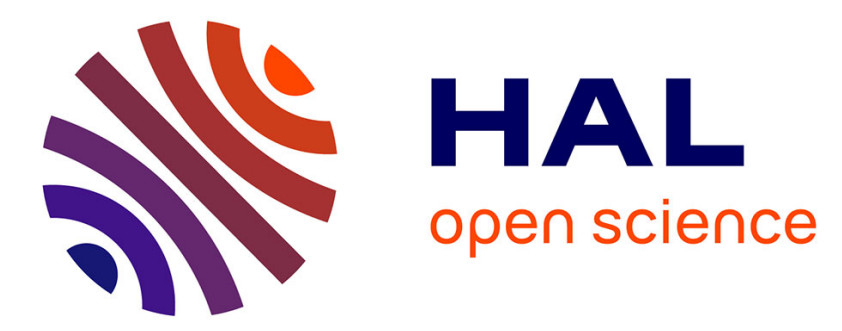

\title{
Electrical characterization of sipos mesa power transistors electric field repartition in the collector-base junction
}

J.-F. Bresse, E. Khalil, M. Savelli, J.B. Quoirin, A. Peyre-Lavigne

\section{To cite this version:}

J.-F. Bresse, E. Khalil, M. Savelli, J.B. Quoirin, A. Peyre-Lavigne. Electrical characterization of sipos mesa power transistors electric field repartition in the collector-base junction. Revue de Physique Appliquée, 1978, 13 (12), pp.733-736. 10.1051/rphysap:019780013012073300 . jpa-00244536

\section{HAL Id: jpa-00244536 https://hal.science/jpa-00244536}

Submitted on 1 Jan 1978

HAL is a multi-disciplinary open access archive for the deposit and dissemination of scientific research documents, whether they are published or not. The documents may come from teaching and research institutions in France or abroad, or from public or private research centers.
L'archive ouverte pluridisciplinaire HAL, est destinée au dépôt et à la diffusion de documents scientifiques de niveau recherche, publiés ou non, émanant des établissements d'enseignement et de recherche français ou étrangers, des laboratoires publics ou privés. 


\title{
ELECTRICAL CHARACTERIZATION OF SIPOS MESA POWER TRANSISTORS ELECTRIC FIELD REPARTITION IN THE COLLECTOR-BASE JUNCTION
}

\author{
J. F. BRESSE, E. KHALIL, M. SAVELLI
}

U.S.T.L., pl. E.-Bataillon, 34060 Montpellier, France

J. B. QUOIRIN and A. PEYRE-LAVIGNE

SESCOSEM, avenue C.-Pelletan, 13160 Aix en Provence, France

\begin{abstract}
Résumé. - Des transistors de puissance largement biseautés, fabriqués en méthode mesa par attaque chimique et recouverts de SIPOS ont été testés électriquement en utilisant le microscope électronique à balayage en mode courant induit. Des courbes de multiplication ont pu être obtenues dans la zone de charge d'espace de la jonction collecteur-base polarisée en inverse lorsque le faisceau balaye perpendiculairement le plan de la jonction. Ceci permet la détermination de la répartition du champ électrique dans la zone de charge d'espace pour un champ supérieur à $10^{5} \mathrm{~V} / \mathrm{cm}$.
\end{abstract}

\begin{abstract}
SIPOS mesa power transistors with large negative bevel angle, obtained by chemical etching, have been electrically tested especially using Scanning Electron Microscopy (S.E.M.) in Electron Beam Induced Current (E.B.I.C.) mode. Multiplication curves can be obtained in the space charge region when the beam scans over the reverse biased collector-base junction which allows the determination of the electric field repartition as function of reverse bias (when a multiplication effect occurs).
\end{abstract}

1. Introduction. - Recently, the n-p-n high voltage transistors showing high reliability have been developped by using semi-insulating or doped polycristalline silicon (SIPOS) films for the surface passivation and protection layer. Very long lifetime can be achieved for the device performance even in temperature (for example $1000 \mathrm{~h}$ at $120^{\circ} \mathrm{C}$ ) as compared to a transistor made by a planar method. Usually, SIPOS is deposited on a deep-etched groove mesa which corresponds qualitatively to the same effects with a large negative bevel technique in our case (N-P ${ }^{+}-\mathrm{N}$ transistor). Only a few work for fabrication process and studies of this kind of power transistors are reported in litterature [1,2].

Both degradation resulting from ion migration and surface breakdown of the collector-base junction depend strongly on the electric field maximum value.

Computer solutions of the Poisson's equation have been developed for different geometries of power transistors. Figure 1 shows the situation for a large negative bevel angle which represents the position of the space charge layer; the edge near the surface of the lightly doped moves side towards the metallurgical junction whereas the edge of the heavily doped side moves away.

A computer solution for the overall variations of the peak tangential field stength at the surface with the bevel angle have been calculated first by Davies and Gentry [3].

These variations depend on many factors such as the bevel angle, the impurity distribution, the surface

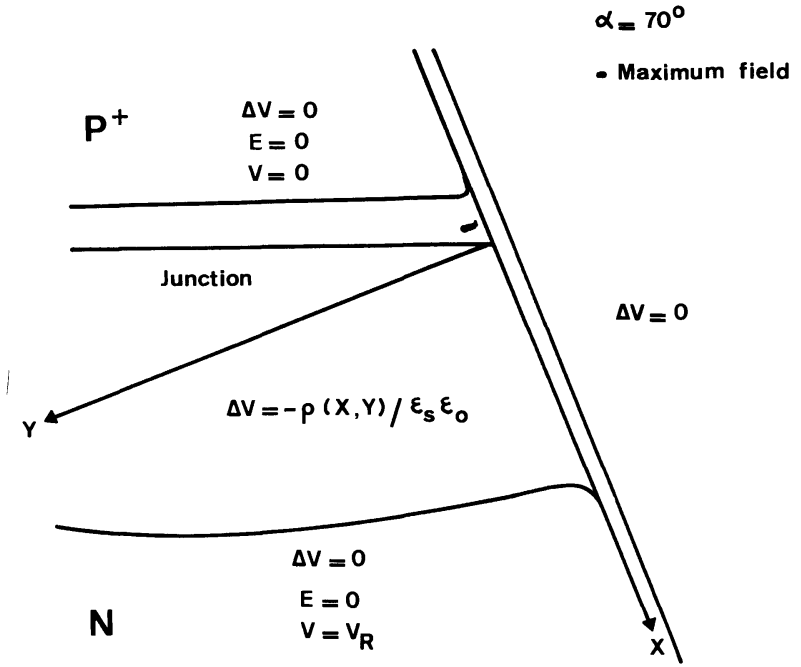

FIG. 1. - Geometry of a large negative bevel angle mesa transistor with space-charge-layer extension and zones corresponding to different Poisson's equation solution $\left(V_{\mathbf{R}}=\right.$ reverse bias, $E=$ electric field).

charge concentration, the dielectric constant of the passivation layer and of course the applied voltage. Analysis of a wide variety of conditions have been the subject of many works $[4,5,6]$.

Figure 1 indicates by a black spot the predicted region of the absolute peak electric field which appears underneath the surface [4]. Both position and magnitude are strongly influenced by properties of the SIPOS 
layer such as the dielectric constant and the effective surface charge (which is influenced by the charge existing at the surface).

This fact has been confirmed experimentally [4] using surface potential measurements by a probing method.

Some other experiments have been made, but only on small negative bevel angle, far from the breakdown conditions.

As a new possibility to test electrically, the S.E.M. has been used to achieve a good resolution in probing the junction.

\section{Electrical characterization of the SIPOS tran-} sistors. - Various devices have been tested for their electrical characteristics ( $I-V$ curves, spreading resistance measurements for doping profiles). Breakdown voltages can achieve 1000 to $1600 \mathrm{~V}$ for $\mathrm{P}^{+}-\mathrm{N}$ devices of substrate resistivities varying from $2 \times 10^{14}$ to $5 \times 10^{13}$ at. $\mathrm{cm}^{-3}$. Different kinds of breakdown can be observed for these devices.

The devices have been observed first with the S.E.M. in the emissive mode to investigate major defects due to a preferential etching at the metallurgical junction. The shape of the mesa made by the chemical etching can be also visualized.

If a reverse bias is applied to the collector-base junction, an Electron Beam Induced Current (E.B.I.C.) can be detected through the external circuit of the device and amplified to obtain images on the screen and profiles which can be drawn on a X-Y recorder.

E.B.I.C. images can be used, as routine, for the failure analysis, which permits to detect the anomalous extensions of the space-charge-layer in some part of the device; the presence of an inversion layer P-side, as reported in electrical modelization, localized defects in the SIPOS layer which can cause different contrasts in the E.B.I.C. image, localized zones where the electric field inside the space-charge region reaches a critical value inducing current multiplication by impact ionization. The effect of surface charges on the electrical behaviour near the breakdown voltage can be also tested especially using the creation of positive charges in the SIPOS layer by the electron beam irradiation.

E.B.I.C. profiles recorded with a KEITHLEY amplifier can give quantitative informations on spacecharge-layer extension and diffusion lengths of minority carriers for $\mathrm{N}$-side and $\mathrm{P}^{+}$-side, and on the multiplication factor $M(x)$ corresponding to the multiplication by impact ionization of holes and electrons in the space-charge-layer. A review of these quantitative investigations has been reported previously [7].

When the beam scans on a line perpendicular to the junction plane, E.B.I.C. profiles can be obtained as function of the reverse bias, as shown on figure 2 for a device with a breakdown of about $600 \mathrm{~V}$.

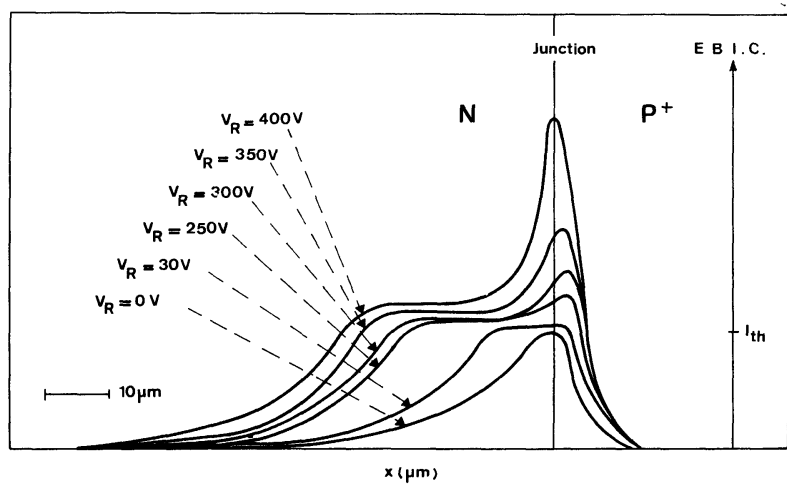

FIG. 2. - Experimental curves of Electron Beam Induced Current on a line perpendicular to the collector-base junction plane for different applied reverse bias.

Extension $\mathbf{N}$ and $\mathbf{P}$-side can be measured directly. Diffusion length are determined using the slope of the curves on the edge of each side of the space-chargelayer. For an electric field higher than $10^{5} \mathrm{~V} / \mathrm{cm}$ a peak corresponding to the multiplication can be recorded.

3. Electric field repartition in the collector-base junction. - The knowledge of the electric field in the space-charge-layer and especially its maximum value is of great importance for the prediction of the breakdown voltage of the collector-base junction which controls the functioning and the use of the power transistor.

3.1 EleCtRiC FIELD PREDICTION. - Using a device modelling, the repartition of the surface electric field can be determined if a mean bevel angle is taken into account in the model with the dielectric constant of the SIPOS and the resistivity of the substrate choosen for a mean value and with an estimation of the doping profiles.

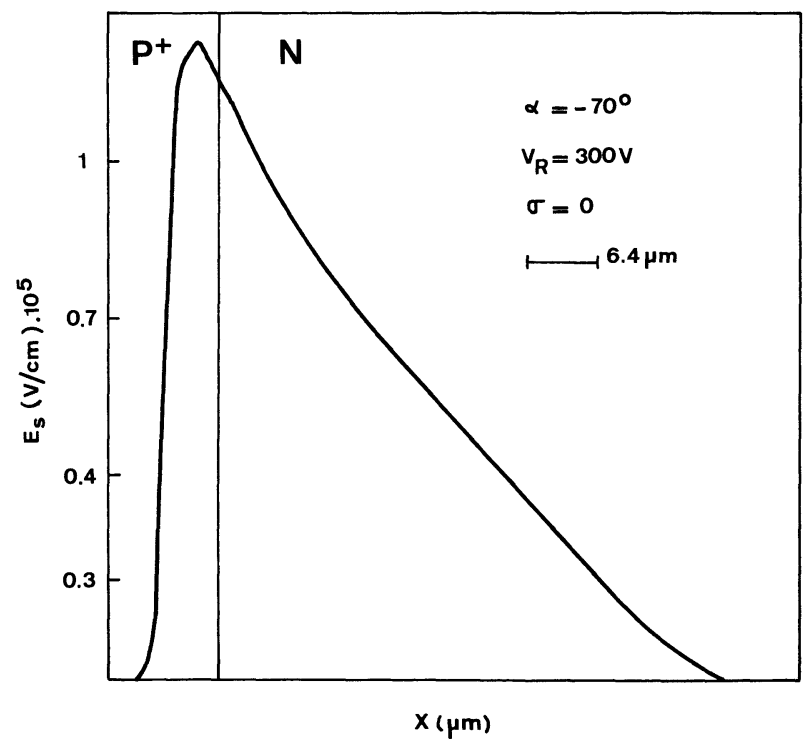

FIG. 3. - Surface electric field repartition in the space-charge-layer of a negative bevelled junction $\left(\alpha=70^{\circ}\right)$ coated with a SIPOS layer $(5000 \AA)$ for an applied voltage of $300 \mathrm{~V}(\sigma=0)$. 
Figure 3 reports the calculated repartition of the surface electric field for negative bevel angle of $70^{\circ}$ and an applied voltage of $300 \mathrm{~V}$ with a substrate resistivity of $10^{14}$ at. $\mathrm{cm}^{-3}$, a double error function for the impurity profile $\left(10^{17}\right.$ at. $\mathrm{cm}^{-3}$ at the surface $)$ without any surface charge $(\sigma=0)$ SIPOS have been represented by a layer of $5000 \AA$ thickness and with a dielectric constant of 14 . The distance corresponds to the bevel surface.

3.2 EleCtric Field DETERMinAtion. - When an electron beam scans across a junction perpendicular to the surface, the beam creates hole-electron pairs and a maximum current $I_{\mathrm{th}}$, corresponding to the complete collection of the created carriers, is observed in the whole space-charge-layer, without any multiplication effect [7]. The current value depends from the beam parameters (energy, intensity) and from the material (essentially the hole-electron pair energy-creation, i.e. $3.6 \mathrm{eV}$ in silicon).

When the applied bias is high enough to induce an electric field higher than $10^{5} \mathrm{~V} / \mathrm{cm}$, a multiplication peak is observed (Fig. 2) and a multiplication factor $M(x)$ in the space-charge-layer can be determined by the ratio collected current over maximum current, $I_{\text {th }}$.

In order to investigate the electric field, two kinds of calculations can be made :

- using the electric field repartition $E(x)$ in the space-charge-layer and some approximations the multiplication factors $M_{\mathrm{n}}(x)$ and $M_{\mathrm{p}}(x)$ can be calculated and compared to the experimental ones,

- using the multiplication factor $M(x)$, taken into account of a justified approximation (neglecting the hole ionization), the electric field repartition can be determined.

3.2.1 Multiplication factor calculation. - Ionization coefficients can be represented as function of the electric field value by formulas :

$$
\alpha=\alpha_{\infty} \exp \left(-\frac{b}{E}\right)
$$

where $\alpha_{\infty}$ and $b$ are given in literature for fields between $10^{5}$ to $5 \times 10^{5} \mathrm{~V} / \mathrm{cm}$. $\left(\alpha_{\mathrm{p}}\right.$ is usually less than $\alpha_{\mathrm{n}}$.)

For a multiplication factor near to 1 , approximate formulas have been given for $M_{\mathrm{n}}$ and $M_{\mathrm{p}}$

$$
M_{\mathrm{n}}=\left(1-\int_{0}^{w} \alpha_{\mathrm{n}} \mathrm{d} x\right)
$$

where $w$ is the space-charge-layer extension.

If the electric field is known, numerical methods of integration permit to calculate the two multiplication factors. For fields up to $5 \times 10^{5} \mathrm{~V} / \mathrm{cm}$, the calculation of $M_{\mathrm{n}}$ and $M_{\mathrm{p}}$ for known field repartition permits to consider that the hole multiplication is negligible compared to the electron one.

This kind of calculation justifies the assumption to neglect the hole multiplication in the next section.
3.2.2 Electric field determination. - If we assume a punctual generation in the space-charge of carriers created by the beam and that the multiplication factor $M(x)$ is due only to the ionization of electrons, we can write :

$$
\log M(x)=\int_{0}^{x} \alpha_{\infty} \exp \left(-\frac{b}{E(y)}\right) \mathrm{d} y .
$$

By derivating this relation, $E(x)$ can be expressed as function of $M(x)$ and $\mathrm{d} M / \mathrm{d} x$

$$
E(x)=b /\left(\log \alpha_{\infty}-\log \left|\frac{1}{M(x)} \times \frac{\mathrm{d} M}{\mathrm{~d} x}\right|\right) .
$$

So, experimentally, at the moment where a multiplication peak appears in the curves of E.B.I.C. in the space-charge-layer, the profiles obtained through the junction like those presented in figure $2\left(V_{\mathrm{R}}=250\right.$, $300,350,400 \mathrm{~V})$, permit to calculate by a numerical method the electric field value. (A smoothing program has been used and a correction has been made to take into account of the shape of the bevel.)

Figures 4 and 5 show the results obtained for two specific devices for reverse bias of $300,400,500 \mathrm{~V}$ (the breakdown voltage was respectively of 600 and $750 \mathrm{~V}$ ). The position of the metallurgical junction is also indicated.

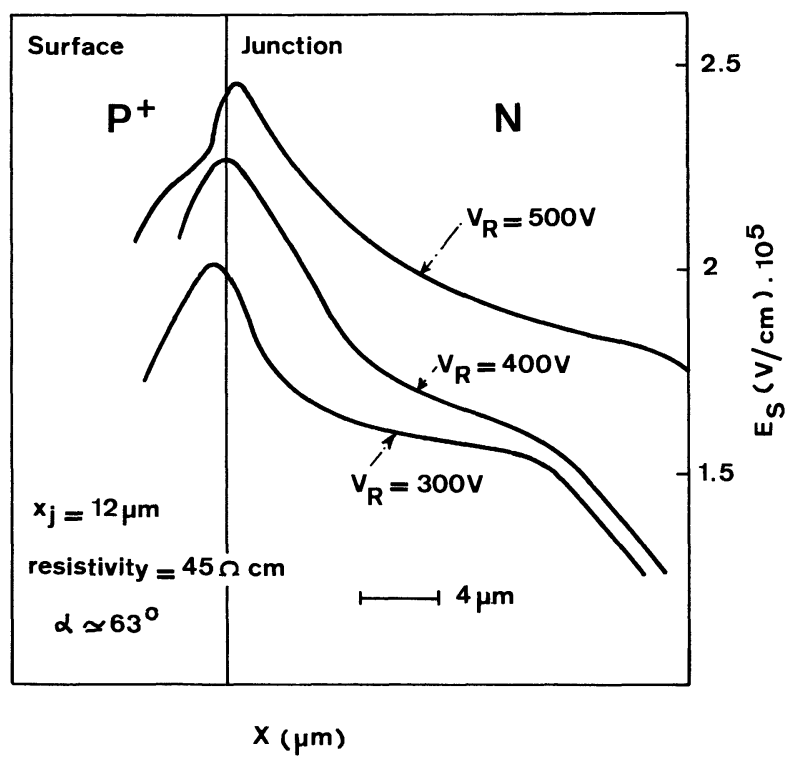

FIG. 4. - Experimental electric field repartition for different bias determined by E.B.I.C. (diffusion depth $x_{j}=12 \mu \mathrm{m}$ ).

- 3.3 Discussion. - In order to test the validity and the precision of the determination of the field repartition, calculations have been made by a numerical method which consists to calculate the multiplication factor corresponding to the repartition of the field determined using the computer program. Figure 6 reports the comparison of the experimental 


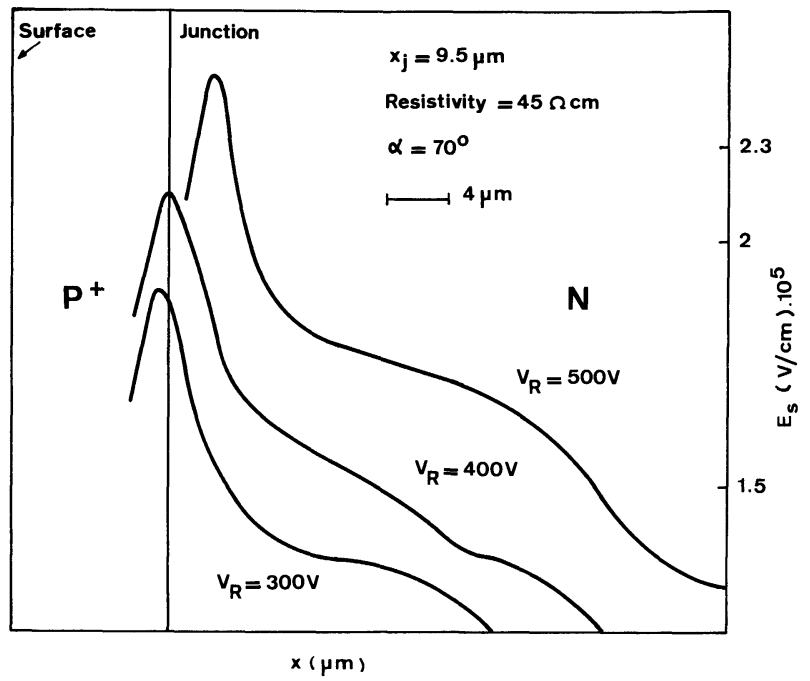

FIG. 5. - Experimental electric field repartition for different bias determined by E.B.I.C. (diffusion depth $x_{j}=9.5 \mu \mathrm{m}$ ).

curve obtained by the E.B.I.C. measurements and the curve obtained after re-calculation of the multiplication factor; so a precision less than $10 \%$ can be achieved.

The results presented on figures 4 and 5 confirm those obtained by the other technique of voltage measurement (by probing with a metal). The magnitude and the position of the peak of the field are similar.

The general shape corresponds to results predicted and experimentally obtained by several authors $[4,5,10]$.

The differences which appear with the theoretical repartition given in figure 3 for the curve at $V_{R}=300 \mathrm{~V}$ (for the magnitude of the peak and the space-chargelayer extension), can be explained by the presence of important surface charges. As reported by Bakowski [5], the magnitude of the peak can be multiplied by a factor of 1.5 to 2.0 by the presence of surface charge of $10^{12} \mathrm{~cm}^{-2}$ and the space layer extension reduced by a factor approximately 1.5 . In this case, the measured field correspond approximately to the maximum field of the device. The peaks are more higher for the device corresponding to figure 5 , which was a device very sensitive to the electron irradiation (an evolution of the space-charge-layer extension has been observed during irradiation).

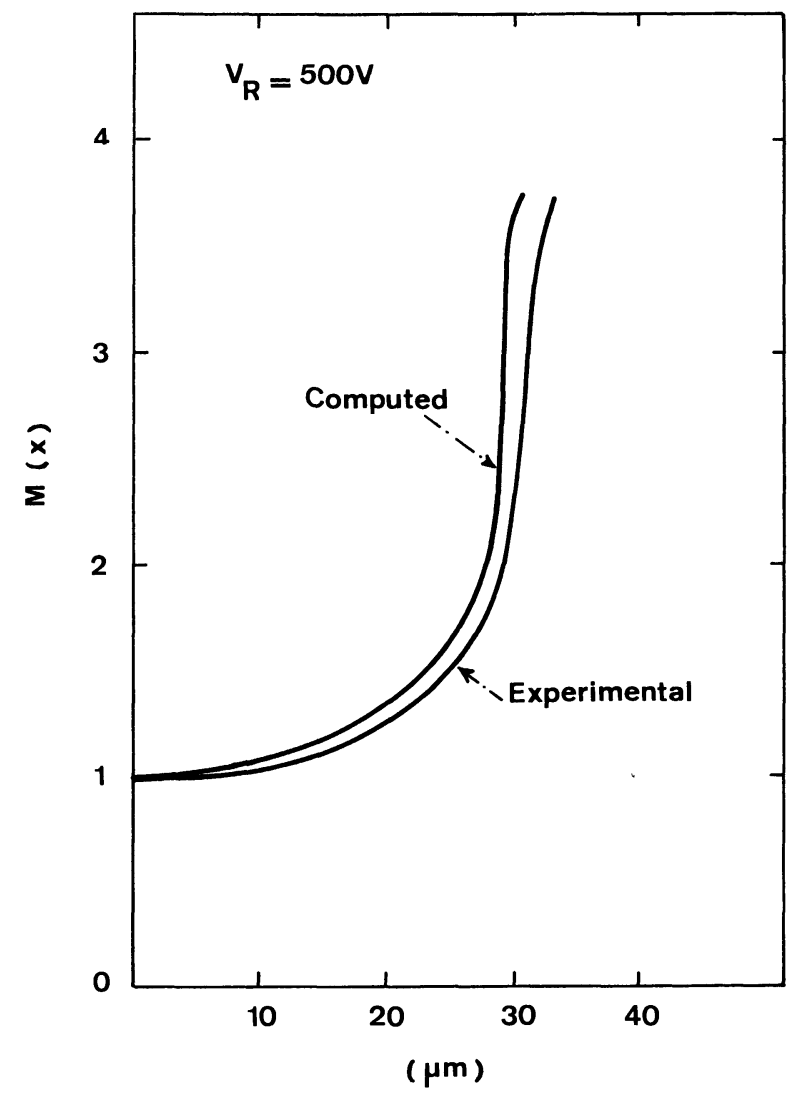

Fig. 6. - Comparison of an experimental curve of the multiplication factor $M(x)$ and the curve obtained by a feed-back technique.

4. Conclusion. - SIPOS mesa power transistors with a large negative bevel angle have been electrically tested and characterized by a new method for this kind of devices. The use of E.B.I.C. on a S.E.M. permits first to visualize electrical defects, as a tool for failure analysis, and second permits to measure different parameters of the collector-base junction, the most important is the electric field repartition in the spacecharge which can be determined with a good precision.

Acknowledgments. - The authors are grateful to Mr. J. Paillé and J. P. Gourret (E.N.S.P. Marseille) for the work of a device modelling and helpfull discussion.

\section{References}

[1] Matteson, F. M., Smith, E. S., I.E.E. Conf. Record, 9th Annual Meeting of I.A.S. (1974) 487.

[2] Matsushita, T., AoKi, T., Ohtsu, T., Yamoto, H., Hayashi, H., Okayama, M., Kawana, Y., I.E.E.E. ED 238 (1976) 826-830.

[3] Davies, R. L., Gentry, F. E., I.E.E.E. Trans. Electron Devices ED 11 (1964) 313.

[4] CORnu, J., I.E.E.E. ED 2040 (1973) 347.

[5] BAKowski, M., Ludstrom, K. I., I.E.E.E. ED 20 (1973) 550.
[6] Adler, M. S., Temple, V. A. K., I.E.E.E. ED 23 (1976) 956. [7] BRESSE, J. F., Scanning Electron Microscopy (I.I.T.R.I. Chicago, U.S.A.) $1977,683$.

[8] Van Overstraten, R., De Man, H., Solid State Electron. 13 (1970) 583.

[9] LeturcQ, P., Thèse d'Etat, Toulouse (1969).

[10] BakowsKi, M., Hansson, B., Solid State Electron. 18 (1975) 651. 